medRxiv preprint doi: https://doi.org/10.1101/2021.09.24.21263966; this version posted September $27,2021$. The copyright holder for this preprint (which was not certified by peer review) is the author/funder, who has granted medRxiv a license to display the preprint in

It is made available under a CC-BY-NC-ND 4.0 International license .

\title{
Effectiveness of rectal artesunate as pre-referral treatment for severe malaria in children $<5$ years of age
}

Manuel W. Hetzel ${ }^{1,2, *}$, Jean Okitawutshu ${ }^{1,3}$, Antoinette Tshefu ${ }^{3}$, Elizabeth Omoluabi ${ }^{4}$, Phyllis Awor ${ }^{5}$, Aita Signorell ${ }^{1,2}$, Nina C. Brunner ${ }^{1,2}$, Jean-Claude Kalenga ${ }^{3}$, Babatunde Akano ${ }^{4}$, Kazeem Ayodeji ${ }^{4}$, Charles Okon ${ }^{4}$, Ocheche Yusuf $^{4}$, Proscovia Athieno ${ }^{5}$, Joseph Kimera ${ }^{5}$, Gloria Tumukunde ${ }^{5}$, Irene Angiro ${ }^{5}$, Giulia Delvento ${ }^{1,2}$, Tristan Lee ${ }^{1,2}$, Mark Lambiris ${ }^{1,2}$, Marek Kwiatkowski ${ }^{1,2}$, Nadja Cereghetti ${ }^{1,2}$, Theodoor Visser ${ }^{6}$, Harriet G. Napier ${ }^{6}$, Justin M. Cohen ${ }^{6}$, Valentina Buj ${ }^{1,7}$, Christian Burri ${ }^{1,2, \#}$, Christian Lengeler ${ }^{1,2, \#}$

1) Swiss Tropical and Public Health Institute, Basel, Switzerland

2) University of Basel, Basel, Switzerland

${ }^{3)}$ Kinshasa School of Public Health, Kinshasa, Democratic Republic of the Congo

4) Akena Associates, Abuja, Nigeria

${ }^{5)}$ Makerere University School of Public Health, Kampala, Uganda

6) Clinton Health Access Initiative, Boston, MA, USA

7) UNICEF, New York, NY, USA

*Corresponding author: manuel.hetzel@swisstph.ch

\#Equal contribution

NOTE: This preprint reports new research that has not been certified by peer review and should not be used to guide clinical practice. 
medRxiv preprint doi: https://doi.org/10.1101/2021.09.24.21263966; this version posted September $27,2021$. The copyright holder for this preprint (which was not certified by peer review) is the author/funder, who has granted medRxiv a license to display the preprint in It is made available under a CC-BY-NC-ND 4.0 International license.

\section{Abstract}

\section{Background}

To prevent child deaths from severe malaria, early parenteral treatment is essential. Yet, in remote rural areas, higher-level facilities offering parenteral antimalarials are often difficult to access. A randomised controlled trial found pre-referral rectal artesunate (RAS) to reduce death and disability in children who delay arriving at a referral facility. This study examined the effectiveness of pre-referral RAS treatment in established community-based health care systems.

\section{Methods}

An observational study accompanied the roll-out of RAS in the Democratic Republic of the Congo, Nigeria and Uganda. Children $<5$ years presenting to a community-based health provider with a positive malaria test and signs of severe malaria were followed-up during admission and after 28 days to assess their health status and treatment history. The primary outcome was death; covariates of interest included RAS use, referral completion, and postreferral treatment.

\section{Findings}

Post-roll-out, RAS was administered to $88 \%$ of patients in DRC, 52\% in Nigeria, and 70\% in Uganda. The overall case fatality rate (CFR) was 6.7\% (135/2011) in DRC, 11.7\% (69/589) in Nigeria, and 0.5\% (19/3686) in Uganda; 865/6286 patients were sick at follow-up. In all countries, the CFR was higher after RAS-roll-out (6.7 vs. 6.6\% in DRC, 16.1 vs. $4.2 \%$ in Nigeria, 0.7 vs. $0.3 \%$ in Uganda). In DRC and Nigeria, children receiving RAS were more likely to die than those not receiving RAS ( $\mathrm{aOR}=3.31,95 \%$ CI 1.43-7.65 and aOR $=2.42,95 \%$ CI 1.25-4.70, respectively). In Uganda, RAS users were less likely to be dead or sick at follow-up (aOR $=0.61,95 \%$ CI 0.46 0.80). Post-referral parenteral antimalarials were protective in all countries; however, the effect of ACT administration was inconsistent.

\section{Interpretation}

RAS pre-referral treatment had no beneficial effect on child survival in three highly malaria endemic settings. RAS is unlikely to reduce malaria deaths unless health system shortfalls such as referral and post-referral treatment are addressed. 
medRxiv preprint doi: https://doi.org/10.1101/2021.09.24.21263966; this version posted September 27, 2021. The copyright holder for this preprint (which was not certified by peer review) is the author/funder, who has granted medRxiv a license to display the preprint in

It is made available under a CC-BY-NC-ND 4.0 International license.

\section{Introduction}

Of the estimated 400000 annual malaria deaths, the majority occur in children $<5$ years of age living in SubSaharan Africa. ${ }^{1}$ Progress towards further reducing malaria's death toll has stalled in recent years and new and complementary approaches are needed to make progress towards global and national malaria elimination targets. ${ }^{1}$ Access to prompt treatment with parenteral artesunate followed by an oral artemisinin-based combination therapy (ACT) alongside the management of complications can save a child suffering from a life-threatening episode of severe malaria. ${ }^{2}$

Usually, only secondary or tertiary health facilities have inpatient wards with the capacity to manage a child with severe malaria comprehensively. Primary health centres (PHC) are often neither equipped nor allowed to administer injections and community health workers (CHW) are only trained to administer oral treatment for uncomplicated malaria episodes and are not qualified to diagnose or treat severe malaria. Integrated Community Case Management (iCCM) programmes instruct CHWs to identify children with danger signs of severe illness (including those indicative of severe malaria) and then immediately refer the child to the nearest health facility. ${ }^{3}$ Children are therefore more likely to suffer from fatal or debilitating consequences of severe malaria in areas where the services of higher-level health facilities are difficult to access. ${ }^{4,5}$

At primary health care level, options to manage severe malaria are typically limited to pre-referral treatment. The World Health Organization (WHO) recommends a single dose of intramuscular (IM) artesunate, or, if injections are not available and the patient is $<6$ years of age, a single rectal dose of artesunate, followed by immediate referral to a higher-level health facility. ${ }^{2}$ Rectal artesunate (RAS) rapidly reduces the malaria parasite load ${ }^{6}$ and in a placebo-controlled randomized trial conducted in Bangladesh, Ghana and Tanzania, the use of pre-referral RAS was found to reduce case fatality of an episode of broadly defined severe malaria by $26 \%$ (risk ratio [RR] 0.74 , 95\% CI 0.59-0.93) in children below 6 years of age. ${ }^{7,8}$ In children who took more than 6 hours to reach a higherlevel facility, RAS reduced death and permanent disability by about 50\% (RR 0.49, 95\% CI 0.32-0.77). ${ }^{7}$

Evidence from a single randomized controlled trial is unlikely to reflect the real-world effect of rolling out RAS at scale ${ }^{9}$ and offers limited operational guidance on the optimal way of introducing RAS. The community-wide exposure-response relationship is complex and affected by the broader health system context. ${ }^{10}$ Previously, the unavailability of a World Health Organization (WHO) prequalified product hampered the generation of real-world evidence of the effectiveness of RAS. With two RAS formulations obtaining prequalification since 2018 and an increasing number of malaria control programmes ordering RAS, ${ }^{11,12}$ there was an urgent need to generate evidence of the impact of introducing pre-referral RAS in routine clinical practice. The potential of RAS to prevent malaria deaths in high-burden settings should be ascertained to establish the role of this intervention in the quest to reduce malaria mortality by $90 \%$ by $2030 .^{13}$

Here, we report on principal findings of the Community Access to Rectal Artesunate for Malaria (CARAMAL) Project, an observational study accompanying the large-scale introduction of pre-referral quality-assured RAS in established community-based health care systems in the Democratic Republic of the Congo (DRC), Nigeria, and Uganda. 
medRxiv preprint doi: https://doi.org/10.1101/2021.09.24.21263966; this version posted September 27, 2021. The copyright holder for this preprint (which was not certified by peer review) is the author/funder, who has granted medRxiv a license to display the preprint in

It is made available under a CC-BY-NC-ND 4.0 International license .

\section{Methods}

\section{Study design}

This was an observational study accompanying the roll-out of pre-referral RAS through CHWs implementing iCCM, and PHCs. The research team conducted the investigations independently; the training of health care providers, behaviour change and communication (BCC) activities, and continuous supply of RAS was the responsibility of local health authorities and UNICEF. Data collection started 8-10 months before RAS roll-out and covered 15-17 months of the post-roll-out period.

\section{Setting}

The study was conducted in three Health Zones (Ipamu, Kenge and Kingandu) in DRC, three Local Government Areas (Fufore, Mayo-Belwa and Song) of Adamawa State in Nigeria, and three districts (Kole, Kwania and Oyam) in Uganda. The total population of the study areas amounted to 2.5 million people including 476,000 (19\%) children <5 years of age (Supplementary Table S1). Curative health services were provided by CHWs implementing iCCM, PHCs, and referral health facilities. Further details of the study sites can be found elsewhere (manuscript in preparation).

\section{Participants and procedures}

Children $<5$ years presenting to a $\mathrm{CHW}$ or PHC with a history of fever plus at least one general danger sign according to national iCCM guidelines (Supplementary Table S1), were provisionally enrolled in the study. These enrolment criteria conform with iCCM criteria for administering RAS. A malaria rapid diagnostic test (mRDT) was performed for study purposes. Health care providers reported each provisional enrolment to the local study coordinator, who included the patient in the study database and scheduled a follow-up visit 28 days after provisional enrolment. Reporting procedures were setting-specific but included in all sites regular pro-active contacts between the study team and enrolling CHWs and PHCs, during which patient characteristics and information on RAS administration were extracted from provider records. Day 28 visits were carried out at the patient's home by trained study staff. Home visits included structured interviews with the patient's caregiver to record the health status and retrospectively elicit the history of signs and symptoms, treatment seeking behaviour, and administration of antimalarials including RAS. Study participants who were sick during the home visits were referred to the nearest health facility for treatment. Interviews with caregivers of deceased children, which included details on the circumstances of death, were postponed for up to one month to respect the mourning period. A mRDT (CareStart or SD Bioline, brand as per routine practice) was performed and haemoglobin concentration was measured (HemoCue hand-held photometer) on capillary blood collected by a single finger or heel prick. Patients who were successfully referred from a CHW or PHC to the main referral health facilities in the study areas were monitored during their admission. All procedures and outcomes during admission were recorded in real-time by facility-based study staff.

Data was collected on tablets using structured electronic forms in ODK Collect (https://opendatakit.org/). The secure ODK Aggregate server was hosted at the Swiss Tropical and Public Health Institute. 
medRxiv preprint doi: https://doi.org/10.1101/2021.09.24.21263966; this version posted September 27, 2021. The copyright holder for this preprint (which was not certified by peer review) is the author/funder, who has granted medRxiv a license to display the preprint in

It is made available under a CC-BY-NC-ND 4.0 International license.

CHWs and PHCs were sensitized and trained about the study during dedicated workshops. All study staff members underwent extensive training on study purpose, informed consent administration, and field data collection procedures.

\section{Outcomes}

Death within 28 days of provisional enrolment was the primary study outcome. A secondary outcome was caregiver-reported illness of the child on day 28 (including both acute episodes and ongoing illness). Malaria RDTpositivity and haemoglobin $(\mathrm{Hb})$ concentration were complementary indicators of morbidity on day 28 . Exposures of interest included RAS use, completed referral to a referral health facility with inpatient ward (Supplementary Table S1), treatment with a parenteral antimalarial, and treatment with an artemisinin-based combination therapy.

\section{Statistics}

Assuming a pre-RAS case fatality rate (CFR) of $6 \%$ (historical CFR for severe malaria: $2.8 \%$ DRC, ${ }^{14} 8.5 \%$ AQUAMAT ${ }^{15}$ ) a minimum of 6032 cases of suspected severe malaria were required to detect a $30 \%$ reduction in CFR between a 6 months pre-RAS and 18 months post-RAS period with $80 \%$ power and $\alpha=0.05 .{ }^{16}$

The analyses included enrolled patients with an acute fever or history of fever, at least one national iCCM general danger sign confirmed during the home visit interview (Supplementary Table S1), and successful follow-up 28 days after preliminary enrolment. Deaths were considered up to 3 days after the official day 28.

Outcomes were calculated for each country as overall proportions, for the pre-RAS and post-RAS periods, and for RAS-users and non-users. Proportions were compared by chi-square tests. Country-specific logistic regression models were developed to estimate the unadjusted and adjusted association of the outcomes 'dead' and 'dead or sick' with RAS use. The enrolling provider or a village proxy was included in all models as a random effect. The set of adjustments varied between countries depending on the country context and the number of events available to analyse. Information on RAS administration is based on consolidated health worker records and caregiver reports.

Data analysis was performed in Stata/SE 15.1 and 16.1.

\section{Ethics}

The CARAMAL study protocol was approved by the Research Ethics Review Committee of the World Health Organization (WHO ERC, No. ERC.0003008), the Ethics Committee of the University of Kinshasa School of Public Health (No. 012/2018), the Health Research Ethics Committee of the Adamawa State Ministry of Health (S/MoH/1131/I), the National Health Research Ethics Committee of Nigeria (NHREC/01/01/2007-05/05/2018), the Higher Degrees, Research and Ethics Committee of the Makerere University School of Public Health (No. 548), the Uganda National Council for Science and Technology (UNCST, No. SS 4534), and the Scientific and Ethical Review Committee of CHAI (No. 112, 21 Nov 2017). The study is registered on ClinicalTrials.gov 
medRxiv preprint doi: https://doi.org/10.1101/2021.09.24.21263966; this version posted September 27, 2021. The copyright holder for this preprint (which was not certified by peer review) is the author/funder, who has granted medRxiv a license to display the preprint in

It is made available under a CC-BY-NC-ND 4.0 International license.

(NCT03568344). Only patients whose caregivers provided written informed consent during the first contact with the study team (at the referral facility or during home visit) were enrolled in the study.

\section{Results}

\section{Participants}

Between April 2018 and July 2020, 8365 patients were provisionally enrolled by a CHW or PHC. Of these, 772 (9\%) were not followed-up or did not provide informed consent, $365(4 \%)$ had no record of a positive mRDT, and $942(11 \%)$ did not fulfil all inclusion criteria. Hence, 6286 patients with suspected severe malaria were included in this analysis, of whom 3402 were treated with RAS (Supplementary Figure S1). Patients in Nigeria were on average older and more frequently male than in the other countries. Age and sex distributions did not differ between RAS users and non-users, except in DRC, where RAS users were slightly older (Table 1). Danger signs reported at enrolment differed between the three countries and in some instances between RAS users and non-users. In DRC, a majority of patients were enrolled at PHCs; in Uganda, enrolments were exclusively from CHWs.

\section{Rectal artesunate intervention and continuum of care}

RAS distribution to CHWs and PHCs started between March and April 2019. Thereafter, RAS was administered, on average, to $88 \%$ of study patients in DRC, $52 \%$ in Nigeria, and $70 \%$ in Uganda. Coverage fluctuated strongly in Nigeria and uptake was slow in the first six months in Uganda (Figure 1).

Treatment and referral patterns differed between the countries (Table 2). Study children in Nigeria were least likely to complete referral. Most children who completed referral did so within one day. In the referral facilities monitored by study nurses, post-referral treatment with parenteral antimalarials followed by an ACT was not universally practised. None of the study children in Nigeria received an ACT during their in-patient time. More details on referral completion and post-referral treatment in the study area are published elsewhere (manuscript in preparation). 
Table 1. Study patient characteristics by country and rectal artesunate use

\begin{tabular}{|c|c|c|c|c|c|c|c|c|c|}
\hline \multirow{2}{*}{$\begin{array}{l}\text { Background } \\
\text { Characteristic }\end{array}$} & \multicolumn{3}{|c|}{ DRC } & \multicolumn{3}{|c|}{ Nigeria } & \multicolumn{3}{|c|}{ Uganda } \\
\hline & $\begin{array}{l}\text { No RAS } \\
(N=475)\end{array}$ & $\begin{array}{c}\text { RAS } \\
(\mathrm{N}=1536)\end{array}$ & P-value & $\begin{array}{l}\text { No RAS } \\
(\mathbf{N}=391)\end{array}$ & $\begin{array}{c}\text { RAS } \\
(\mathbf{N}=198)\end{array}$ & P-value & $\begin{array}{c}\text { No RAS } \\
(\mathrm{N}=2018)\end{array}$ & $\begin{array}{c}\text { RAS } \\
(\mathrm{N}=1668)\end{array}$ & P-value \\
\hline Female, n (\%) & $221(47)$ & $719(47)$ & 0.91 & $151(39)$ & $86(43)$ & 0.26 & $944(47)$ & $781(47)$ & 0.98 \\
\hline Mean age in years (SD) & $1.6(1.3)$ & $1.8(1.3)$ & 0.002 & $2.0(1.2)$ & $1.9(1.2)$ & 0.67 & $1.8(1.3)$ & $1.8(1.2)$ & 0.55 \\
\hline \multicolumn{10}{|l|}{ Danger sign at enrolment, $\mathrm{n}(\%)$} \\
\hline Convulsions & $248(52)$ & $884(58)$ & 0.04 & $233(60)$ & $154(78)$ & $<0.001$ & $590(29)$ & $829(50)$ & $<0.001$ \\
\hline Unusually sleepy/unconscious & $175(37)$ & $322(21)$ & $<0.001$ & $249(64)$ & $119(60)$ & 0.40 & $1239(61)$ & $1480(89)$ & $<0.001$ \\
\hline Not able to drink or feed & $322(68)$ & $704(46)$ & $<0.001$ & $252(64)$ & $107(54)$ & 0.01 & $1152(57)$ & $1262(76)$ & $<0.001$ \\
\hline Vomiting everything & $44(9)$ & $160(10)$ & 0.47 & $284(73)$ & $103(52)$ & $<0.001$ & $1271(63)$ & $1038(62)$ & 0.64 \\
\hline \multicolumn{10}{|l|}{ Enrolment location, $\mathrm{n}(\%)$} \\
\hline Community health worker & $21(4)$ & $69(4)$ & & $227(58)$ & $87(44)$ & & $2018(100)$ & $1668(100)$ & \\
\hline Primary health centre & $454(96)$ & $1467(96)$ & 0.95 & $164(42)$ & $111(56)$ & 0.001 & & & \\
\hline \multicolumn{10}{|l|}{ RAS implementation period, $\mathrm{n}(\%)$} \\
\hline Pre-RAS & $302(64)$ & $2(0)$ & & $217(55)$ & $0(0)$ & & $1394(69)$ & $47(3)$ & \\
\hline Post-RAS & $173(36)$ & $1534(100)$ & $<0.001$ & $174(45)$ & $198(100)$ & $<0.001$ & $624(31)$ & $1621(97)$ & $<0.001$ \\
\hline \multicolumn{10}{|l|}{ Area (DRC/Nigeria/Uganda), n (\%) } \\
\hline Ipamu/Fufore/Kole & $81(17)$ & $556(36)$ & & $185(47)$ & $52(26)$ & & $1303(65)$ & $410(25)$ & \\
\hline Kenge/Mayo-Belwa/Oyam & $207(44)$ & $536(35)$ & & $150(38)$ & $99(50)$ & & $398(20)$ & $576(35)$ & \\
\hline Kingandu/Song/Kwania & $187(39)$ & $444(29)$ & $<0.001$ & $56(14)$ & $47(24)$ & $<0.001$ & $317(16)$ & $682(41)$ & $<0.001$ \\
\hline Rainy season*, n (\%) & $342(72)$ & $738(48)$ & $<0.001$ & $281(72)$ & $159(80)$ & 0.03 & $1441(71)$ & $868(52)$ & $<0.001$ \\
\hline
\end{tabular}

RAS = rectal artesunate; *DRC: October-April; Nigeria: May-October; Uganda: April-October 
medRxiv preprint doi: https://doi.org/10.1101/2021.09.24.21263966; this version posted September 27, 2021. The copyright holder for this preprint (which was not certified by peer review) is the author/funder, who has granted medRxiv a license to display the preprint in

It is made available under a CC-BY-NC-ND 4.0 International license

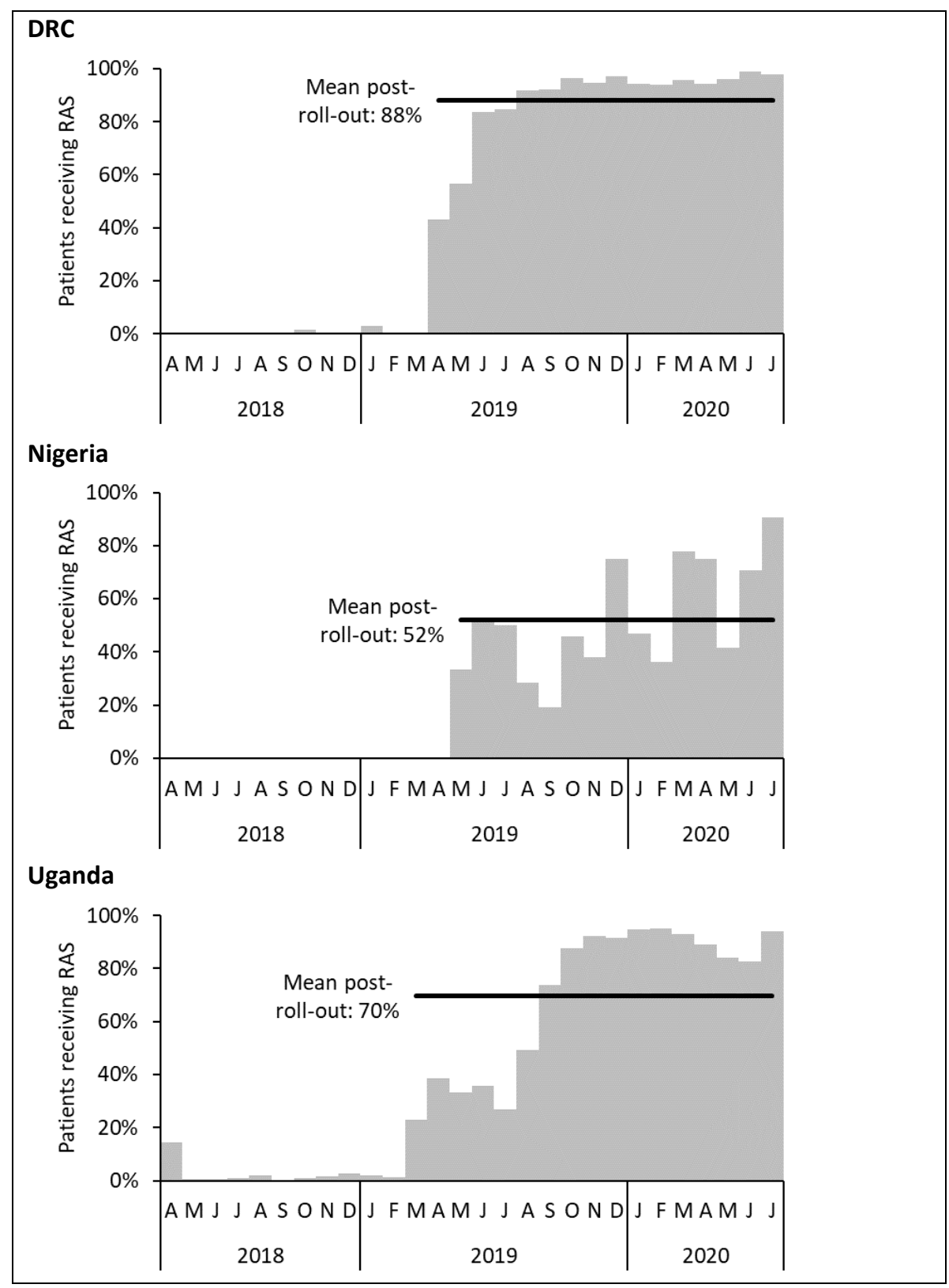

Figure 1. RAS use among study patients, by month 
medRxiv preprint doi: https://doi.org/10.1101/2021.09.24.21263966; this version posted September 27, 2021. The copyright holder for this preprint (which was not certified by peer review) is the author/funder, who has granted medRxiv a license to display the preprint in It is made available under a CC-BY-NC-ND 4.0 International license .

Table 2. Treatment and referral along the continuum of care

\begin{tabular}{|lccc|}
\hline Exposure variables & DRC & Nigeria & Uganda \\
\hline RAS use (N) & $\mathbf{2 0 1 1}$ & $\mathbf{5 8 9}$ & $\mathbf{3 6 8 6}$ \\
\hline Yes (\%) & 76.4 & 33.6 & 45.3 \\
Referral completion to referral health facility (N) & $\mathbf{2 0 1 1}$ & $\mathbf{5 8 9}$ & $\mathbf{3 6 8 6}$ \\
\hline Yes (\%) & 65.0 & 41.3 & 57.3 \\
\hline Unconfirmed (\%) & 2.4 & 12.9 & 0.6 \\
\hline Referral delay (N) & $\mathbf{2 0 1 1}$ & $\mathbf{5 8 9}$ & $\mathbf{3 6 8 6}$ \\
\hline Same or next day (\%) & 47.7 & 33.1 & 50.1 \\
\hline Later than next day (\%) & 14.9 & 5.6 & 4.6 \\
\hline Not completed (\%) & 32.5 & 45.8 & 42.1 \\
\hline Unknown (\%) & 4.9 & 15.5 & 3.2 \\
\hline Post-referral treatment & & & \\
Artesunate injection (N) & $\mathbf{1 2 1 5}$ & $\mathbf{1 7 7}$ & $\mathbf{1 4 2 0}$ \\
\hline Yes (\%) & 78.7 & 94.4 & 43.7 \\
\hline Antimalarial injection** (N) & $\mathbf{1 2 1 5}$ & $\mathbf{1 7 7}$ & $\mathbf{1 4 3 6}$ \\
\hline Yes (\%) & 86.8 & 94.4 & 51.5 \\
\hline ACT (N) & $\mathbf{1 2 1 5}$ & $\mathbf{1 7 7}$ & $\mathbf{2 1 1 1 *}$ \\
\hline Yes (\%) & 68.4 & 0 & 70.9 \\
\hline Antimalarial injection ${ }^{*}$ \& ACT (N) & $\mathbf{1 2 1 5}$ & $\mathbf{1 7 7}$ & $\mathbf{1 3 5 1 *}$ \\
\hline Yes (\%) & 63.8 & 0 & 46.0 \\
\hline
\end{tabular}

Data shown for the entire study period. RAS = rectal artesunate; ACT = artemisinin-based combination therapy;

*in Uganda, this may include medicines administered outside monitored referral facilities; **includes parenteral artesunate, artemether and quinine.

\section{Health status at day 28 follow-up}

\section{Death}

A total of 223 deaths were registered among the study patients (135 in DRC, 69 in Nigeria, 19 in Uganda). The overall CFR was 6.7\% (135/2011) in DRC, 11.7\% (69/589) in Nigeria, and 0.5\% (19/3686) in Uganda (p<0.001) (Table 3). None of the deaths were from an accident or injury. Most deaths occurred in a health facility (DRC $73 \%$, Nigeria 49\%, Uganda 42\%), on the way to a (referral) health facility (DRC 17\%, Nigeria 10\%, Uganda 26\%), and at home (DRC 7\%, Nigeria 35\%, Uganda 32\%). In DRC and Nigeria, deaths occurred over the entire followup period (Figure 2). Deaths occurred later in Nigeria (mean 6.3 days after provisional enrolment) than in DRC (4.2 days) and Uganda (2.4 days) $(\mathrm{p}=0.03)$. While there was no significant change in CFR after the roll-out of RAS in DRC and Uganda (Table 3), an increase was observed in Nigeria among both CHW and PHC enrolments $(\mathrm{RR}=3.5,95 \%$ CI 1.2-10.3 and 2.6, 95\% CI 1.1-6.3, respectively).

\section{IIIness}

In addition, 865 patients were found to be sick on the day of follow-up, with a significant difference between the countries $(\mathrm{p}<0.001)$ (complementary data in Supplementary Figure S2). Conversely, a comparable proportion of patients was healthy in DRC (81\%), Nigeria (83\%), and Uganda (84\%) (p=0.54). Of 6020 patients tested by mRDT 
medRxiv preprint doi: https://doi.org/10.1101/2021.09.24.21263966; this version posted September $27,2021$. The copyright holder for this preprint (which was not certified by peer review) is the author/funder, who has granted medRxiv a license to display the preprint in

It is made available under a CC-BY-NC-ND 4.0 International license .

at follow-up, $44.0 \%$ were positive in DRC, 50.2\% in Nigeria, and 69.5\% in Uganda (Table 3). Those reported sick were significantly more likely to be mRDT-positive than those who were healthy ( $\mathrm{p}<0.001$ ) (Figure 3). In the latter group, HRP2/pLDH combo tests more frequently detected only HRP2 than in sick patients in DRC and Uganda ( $<<0.001$, Supplementary Figure S3), suggesting persistent antigenaemia rather than an active infection.

$\mathrm{Hb}$ concentration measured in 5768 patients at follow-up found a lower mean $\mathrm{Hb}$ in Nigeria $(9.9 \mathrm{~g} / \mathrm{dL})$ than in DRC and Uganda (both $10.3 \mathrm{~g} / \mathrm{dL}, \mathrm{p}<0.001$ ). Sick children in DRC and Uganda were more likely to have severe anaemia $(\mathrm{Hb}<7 \mathrm{~g} / \mathrm{dL})$ than healthy children (both $\mathrm{p}<0.001)$ (Figure 3 and Supplementary Figure S4).

Table 3. Health outcomes at day 28 follow-up by country, RAS implementation phase and RAS use

\begin{tabular}{|c|c|c|c|c|c|c|c|c|c|c|}
\hline & \multicolumn{3}{|l|}{ DRC } & \multicolumn{3}{|l|}{ Nigeria } & \multicolumn{3}{|l|}{ Uganda } & \multirow{2}{*}{$\begin{array}{l}\text { Between- } \\
\text { country } \\
\text { p-value }\end{array}$} \\
\hline & $\mathbf{n} / \mathbf{N}$ & $(\%)$ & $\begin{array}{c}\text { P- } \\
\text { value* }\end{array}$ & $\mathbf{n} / \mathbf{N}$ & $(\%)$ & $\begin{array}{c}\text { P- } \\
\text { value* }\end{array}$ & $\mathbf{n} / \mathbf{N}$ & $(\%)$ & $\begin{array}{c}\text { P- } \\
\text { value* }^{*}\end{array}$ & \\
\hline \multicolumn{11}{|c|}{ Case Fatality Rate } \\
\hline Overall & $135 / 2011$ & $(6.7)$ & & $69 / 589$ & $(11.7)$ & & $19 / 3686$ & $(0.5)$ & & $<0.001$ \\
\hline \multicolumn{11}{|c|}{ Implementation } \\
\hline Pre-RAS & $20 / 304$ & $(6.6)$ & & $9 / 217$ & $(4.2)$ & & $4 / 1441$ & $(0.3)$ & & \\
\hline Post-RAS & $115 / 1707$ & (6.7) & 0.92 & $60 / 372$ & $(16.1)$ & $<0.001$ & $15 / 2245$ & $(0.7)$ & 0.14 & \\
\hline \multicolumn{11}{|l|}{ RAS use } \\
\hline No & $27 / 475$ & (5.7) & & $30 / 391$ & $(7.7)$ & & $12 / 2018$ & $(0.6)$ & & \\
\hline Yes & $108 / 1536$ & $(7.0)$ & 0.34 & $39 / 198$ & $(19.7)$ & $<0.001$ & $7 / 1668$ & $(0.4)$ & 0.45 & \\
\hline \multicolumn{11}{|c|}{ Illness at day 28 follow-up } \\
\hline Overall & $242 / 2011$ & $(12.0)$ & & $34 / 589$ & $(5.8)$ & & $589 / 3686$ & $(16.0)$ & & 0.002 \\
\hline \multicolumn{11}{|c|}{ Implementation } \\
\hline Pre-RAS & $40 / 304$ & $(13.2)$ & & $20 / 217$ & $(9.2)$ & & $299 / 1441$ & $(20.8)$ & & \\
\hline Post-RAS & $202 / 1707$ & $(11.8)$ & 0.59 & $14 / 372$ & $(3.8)$ & 0.007 & $290 / 2245$ & $(12.9)$ & 0.003 & \\
\hline \multicolumn{11}{|l|}{ RAS use } \\
\hline No & $72 / 475$ & $(15.2)$ & & $25 / 391$ & $(6.4)$ & & $428 / 2018$ & $(21.2)$ & & \\
\hline Yes & $170 / 1536$ & $(11.1)$ & 0.04 & $9 / 198$ & $(4.6)$ & 0.30 & $161 / 1668$ & $(9.7)$ & $<0.001$ & \\
\hline \multicolumn{11}{|c|}{ mRDT-positive at day 28 follow-up } \\
\hline Overall & $811 / 1843$ & $(44.0)$ & & $256 / 510$ & $(50.2)$ & & $2547 / 3667$ & $(69.5)$ & & $<0.001$ \\
\hline \multicolumn{11}{|c|}{ Implementation } \\
\hline Pre-RAS & $159 / 284$ & $(56.0)$ & & $97 / 208$ & $(46.6)$ & & $953 / 1437$ & $(66.3)$ & & \\
\hline Post-RAS & $652 / 1559$ & $(41.8)$ & $<0.001$ & $159 / 302$ & $(52.7)$ & 0.27 & $1594 / 2230$ & $(71.5)$ & 0.02 & \\
\hline \multicolumn{11}{|l|}{ RAS use } \\
\hline No & $235 / 444$ & $(52.9)$ & & $168 / 357$ & $(47.1)$ & & $1405 / 2006$ & $(70.0)$ & & \\
\hline Yes & $576 / 1399$ & $(41.2)$ & $<0.001$ & $88 / 153$ & $(57.5)$ & 0.03 & $1142 / 1661$ & $(68.8)$ & 0.44 & \\
\hline \multicolumn{11}{|c|}{ Severe anaemia at day 28 follow-up } \\
\hline Overall & $65 / 1875$ & $(3.5)$ & & $33 / 514$ & $(6.4)$ & & $151 / 3379$ & $(4.5)$ & & 0.054 \\
\hline \multicolumn{11}{|c|}{ Implementation } \\
\hline Pre-RAS & $14 / 284$ & $(4.9)$ & & $21 / 208$ & $(10.1)$ & & $69 / 1256$ & $(5.5)$ & & \\
\hline Post-RAS & $51 / 1591$ & $(3.2)$ & 0.09 & $12 / 306$ & $(3.9)$ & 0.02 & $82 / 2123$ & $(3.9)$ & 0.03 & \\
\hline \multicolumn{11}{|l|}{ RAS use } \\
\hline No & $23 / 447$ & $(5.2)$ & & $24 / 359$ & $(6.7)$ & & $105 / 1817$ & $(5.8)$ & & \\
\hline Yes & $42 / 1428$ & (2.9) & 0.03 & $9 / 155$ & $(5.8)$ & 0.75 & $46 / 1562$ & (2.9) & $<0.001$ & \\
\hline
\end{tabular}

*chi-square test, accounting for clustering at provider level 
medRxiv preprint doi: https://doi.org/10.1101/2021.09.24.21263966; this version posted September $27,2021$. The copyright holder for this preprint (which was not certified by peer review) is the author/funder, who has granted medRxiv a license to display the preprint in It is made available under a CC-BY-NC-ND 4.0 International license .

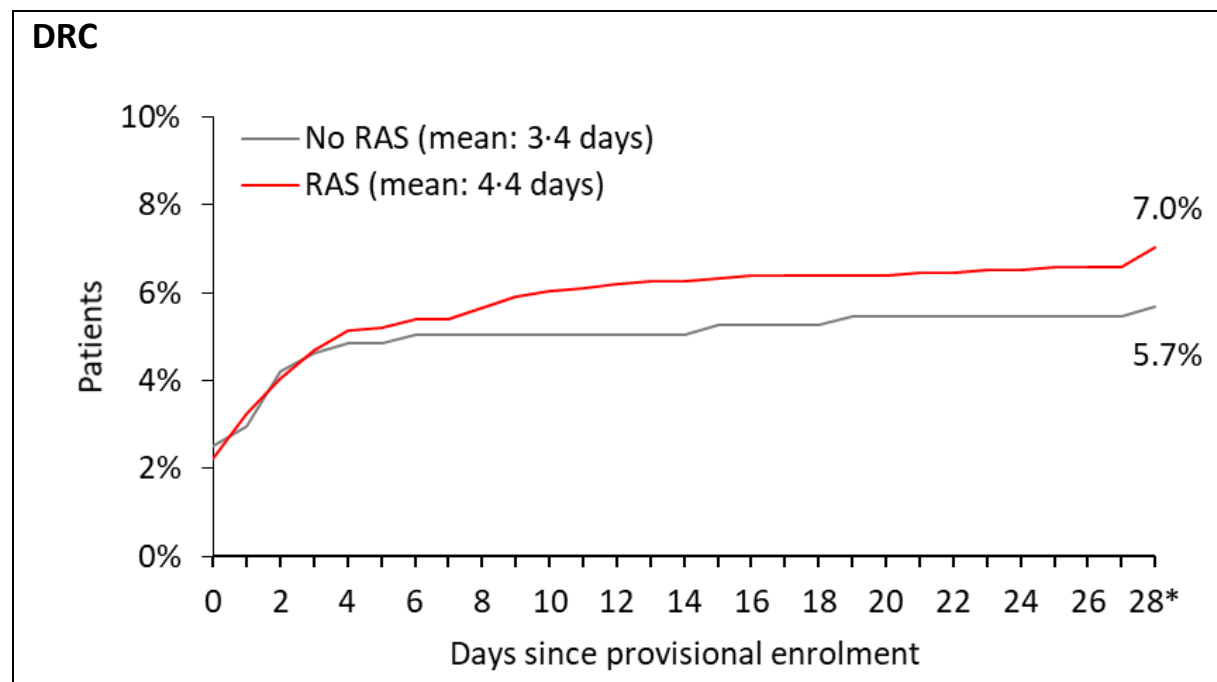

Nigeria

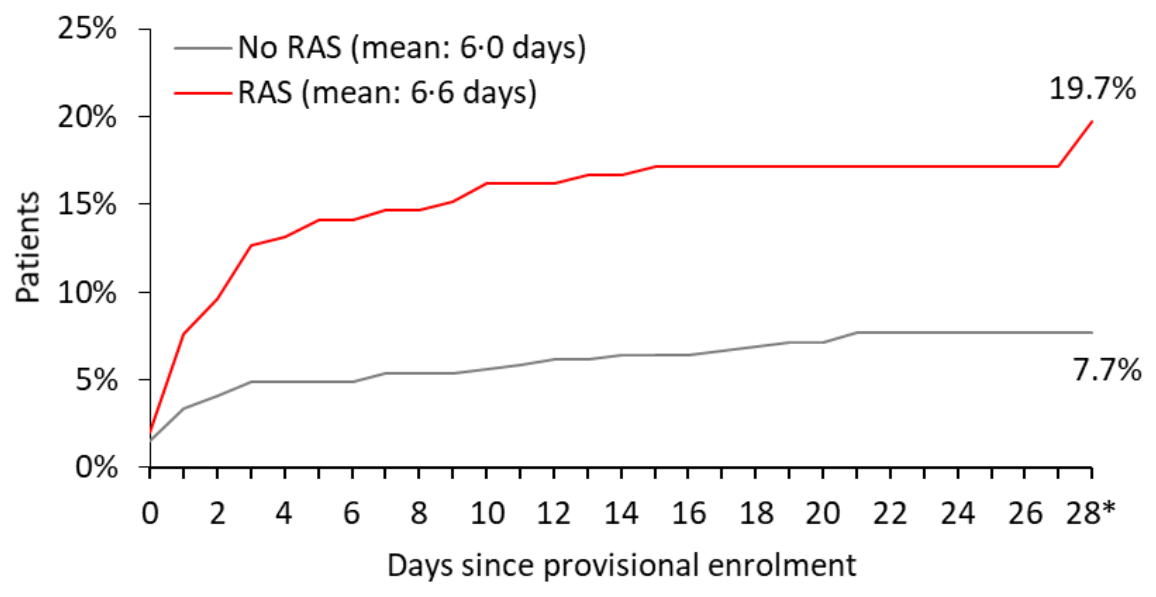

\section{Uganda}

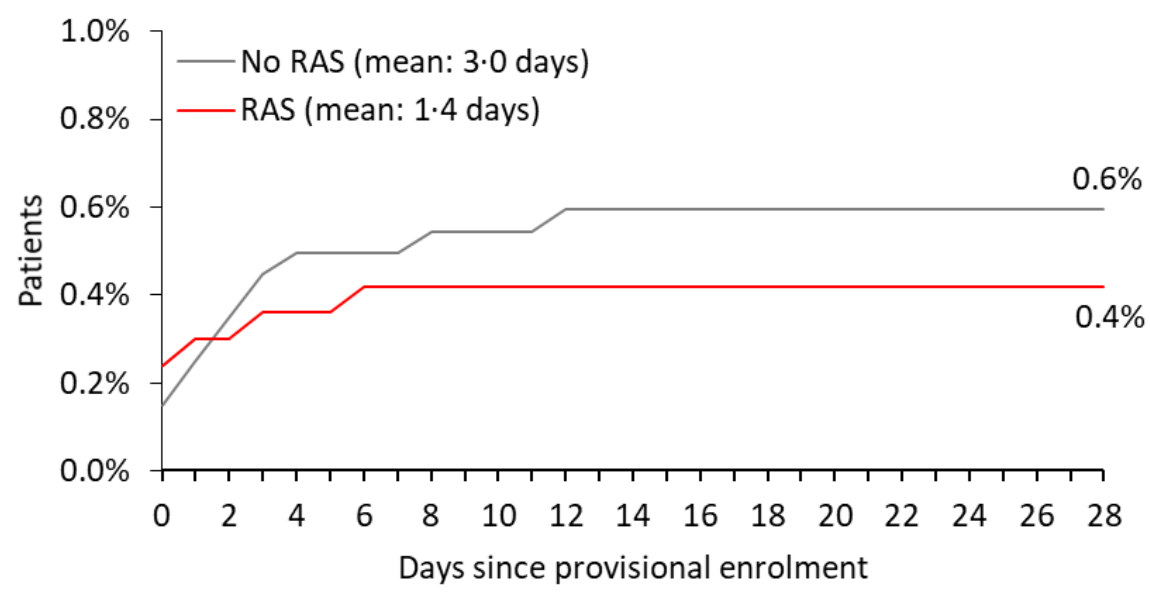

Figure 2. Time to death in days since provisional enrolment (provider attendance) of study participants, by country and RAS use. Note difference in y-axis scales. *deaths occurring up to day 31 were considered. 
(A)

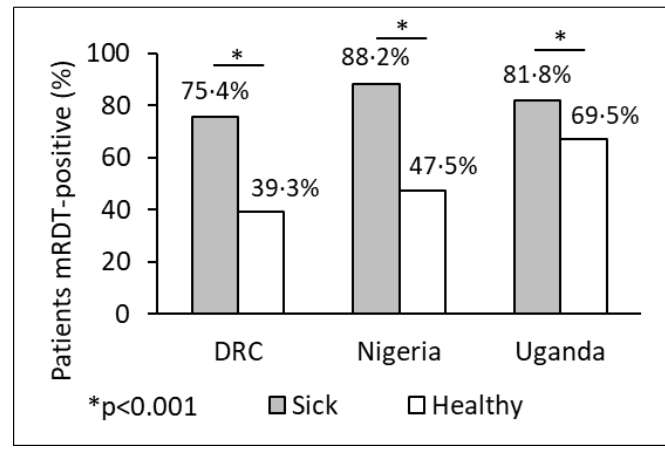

(B)

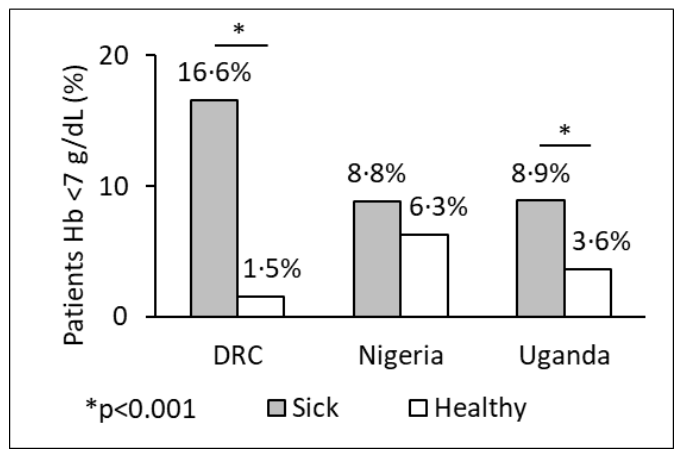

Figure 3. Percent of study patients with (A) a positive mRDT and (B) severe anaemia (Hb $<7$ g/dL) at 28 day follow-up, by health status

\section{Health impact of RAS}

In DRC, there was no evidence of an association of RAS use with CFR (OR $=1.25,95 \%$ CI 0.81-1.93) (Table 4A). After adjusting for covariates including referral completion and post-referral treatment, however, RAS use appeared to have a negative effect on survival ( $\mathrm{aOR}=3.31,95 \% \mathrm{CI} 1.43-7.65)$. On the other hand, children who received RAS were more likely to receive both a parenteral antimalarial and ACT ( $44.9 \%$ vs $22.1 \%$, p < 0.001 ), and patients who received both of these medicines were less likely to die than those who received neither $(\mathrm{aOR}=$ $0.12,95 \%$ CI 0.05-0.26). More broadly, RAS use did not appear to reduce the likelihood of being dead or sick at follow-up (aOR $=0.87,95 \%$ CI 0.58-1.31) (Table 4B). Patients in DRC who did not complete referral were less likely to be dead or sick at follow-up than those who completed referral within one day.

In Nigeria, patients who received RAS were significantly more likely to die (OR $=2.95,95 \%$ CI 1.78-4.90) (Table 4A). The risk of dying was much higher among those enrolled at a PHC compared to a CHW (CFR $=18.5 \%$ vs. $5.7 \%, \mathrm{p}=0.001$ ) (Supplementary Figure S5). Adjusted for enrolling provider, referral completion and post-referral treatment, RAS use remained strongly associated with death $(\mathrm{aOR}=2.42,95 \% \mathrm{CI} 1.25-4.70)$ while administration of a parenteral antimalarial was associated with survival ( $\mathrm{aOR}=0.17,95 \% \mathrm{CI} 0.03-0.93$ ). With the same adjustments, there was weak evidence of an association between RAS use and being dead or sick at follow-up $(\mathrm{aOR}=1.60,95 \% \mathrm{CI} 0.96-2.65)$ and of a negative effect of not completing referral (Table 4B).

In Uganda, in the context of overall low case fatality, no direct association was found between RAS use and death (OR $=0.70,95 \%$ CI 0.29-1.74) (Table 4A). However, patients who received RAS were less likely to be dead or sick at follow-up ( $\mathrm{aOR}=0.61,95 \% \mathrm{CI} 0.46-0.80)$ as were those who were treated with a parenteral antimalarial $(\mathrm{aOR}=0.58,95 \%$ CI $0.46-0.75)$ (Table 4B). Patients in Uganda who did not complete referral were less likely to be dead or sick at follow-up than those who did so promptly. 
Table 4. Association of health outcome at day 28 follow-up and selected predictors, including pre-referral RAS treatment

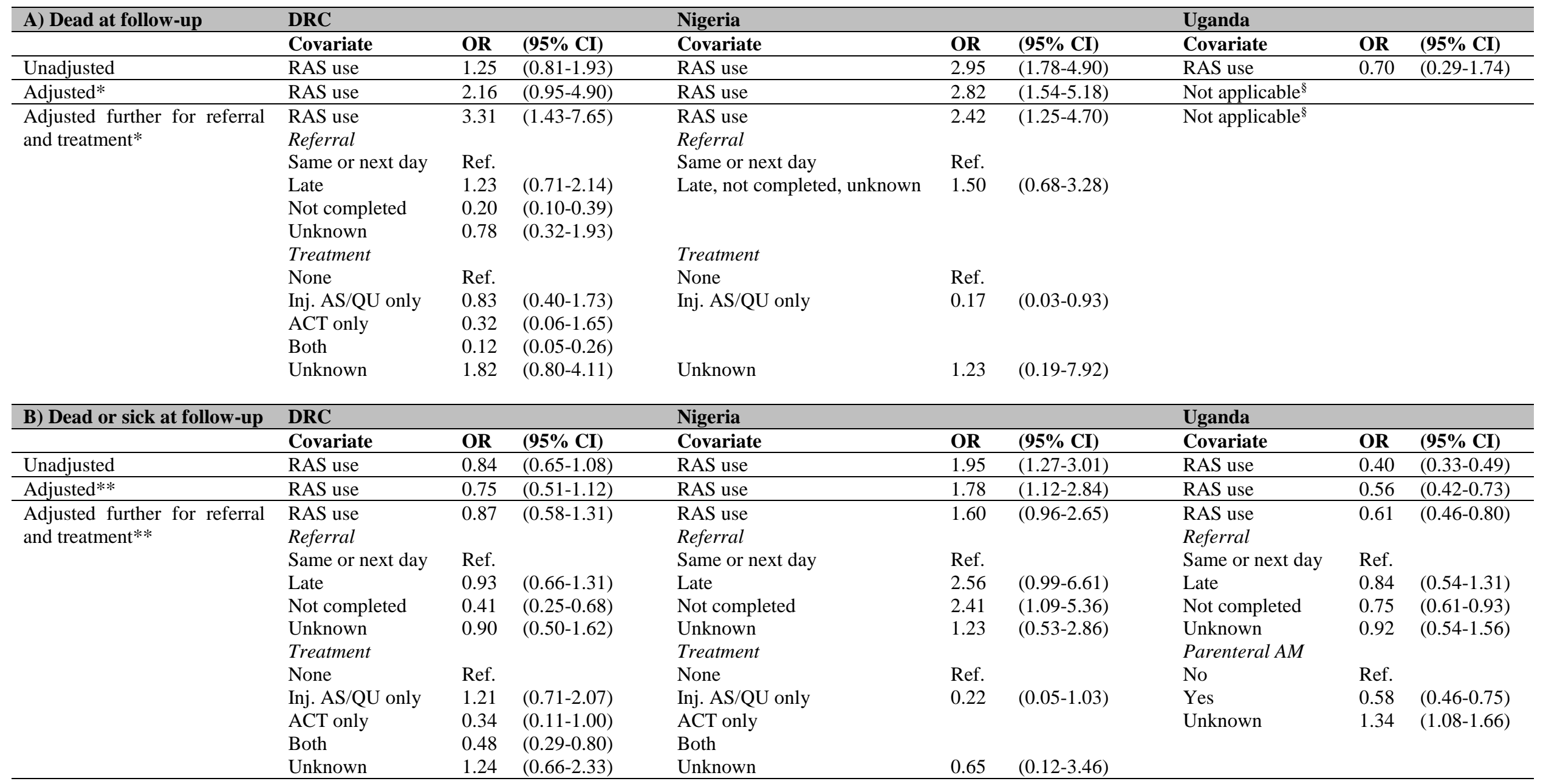

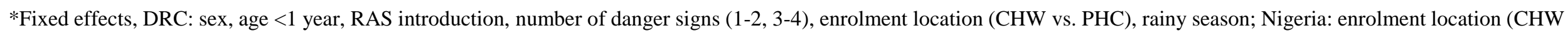

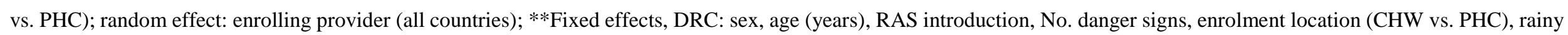

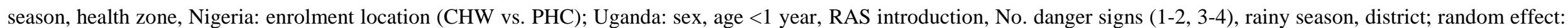

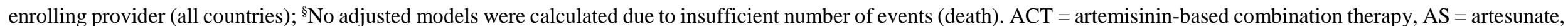
$\mathrm{QU}=$ quinine, $\mathrm{RAS}=$ rectal artesunate 


\section{Discussion}

The current recommendation to use RAS as pre-referral treatment where parenteral alternatives are unavailable is based on a single randomised controlled trial that provides little evidence of the effect of introducing RAS at scale. ${ }^{7-9,17}$ Other studies were implemented as intervention packages including both RAS and a strong support to referral mechanisms. ${ }^{18-20}$ The CARAMAL Project represents the first large-scale assessment of the health impact of introducing RAS in existing community-level health care systems accompanied by only minimal supportive interventions, reflecting the anticipated large-scale roll-out of RAS. ${ }^{12}$ Based on systematic 28 days patient followup, CARAMAL provides robust evidence of the health impact of this intervention in three distinct sub-Saharan African settings with a high burden of malaria, and of health system factors that may promote or hamper the effectiveness of RAS as part of paediatric severe malaria care.

The beneficial effect of RAS pre-referral treatment on survival found in the trial by Gomes et al. ${ }^{7,8}$ could not be replicated in the 'real-world' scenarios of the three study sites. On the contrary, in DRC and Nigeria, patients treated with RAS were more likely to die over the course of the follow-up period. The use of RAS was found to have a slight positive health effect in Uganda, driven primarily by a reduction in children reported sick at followup $(\mathrm{aOR}=0.61)$. Patients who were sick at follow-up had a positive $\mathrm{mRDT}$ or severe anaemia $(\mathrm{Hb}<7 \mathrm{~g} / \mathrm{dL}) \mathrm{more}$ often than those who were healthy. RAS users were less often mRDT-positive (all countries) or severely anaemic (DRC and Uganda) at follow-up.

The increase in CFR associated with the roll-out and use of RAS is unlikely to be a direct result of RAS treatment which was previously shown to be safe and efficacious. ${ }^{21,22}$ It is likely that there are confounding factors on the effect of RAS beyond what the analyses could be adjusted for given the complex interactions between disease severity, treatment seeking behaviour, and care provided. Secular and seasonal trends in disease incidence and severity, as well as an effect of Covid-19 on health seeking and provision of care, may also have played a role. In Nigeria, CFR was highest in children enrolled at PHCs (Supplementary Figure S5) and patients attending PHCs were found to be more severely ill than those attending a CHW (manuscript in preparation). In Uganda, a countrywide increase in malaria was reported in 2019, overlapping with the early RAS implementation phase. Anecdotal evidence suggests that health workers stocking only a small number of RAS doses may have administered RAS preferentially to more severely sick children (CARAMAL Project, unpublished data). The small number of deaths in Uganda did not allow accounting for such potential confounders in the CFR analysis. Due to the communitylevel enrolment strategy in all countries, an expert clinical assessment of patients (incl. diagnosis of co-morbidities that might impact the effectiveness of malaria treatment) was not available for this analysis.

In the absence of comprehensive measures to strengthen the underlying health system implemented synergistically with the introduction of RAS, several factors along the continuum of care may have hampered the effectiveness of RAS. Between $32.5 \%$ and $45.8 \%$ of study patients did not complete referral to an appropriate health facility. In DRC and Nigeria, we found evidence of RAS use having an adverse effect on referral completion (manuscript in preparation). Non-completion of referral after pre-referral treatment with RAS has been reported from other studies, ${ }^{20,23}$ and may prevent patients from obtaining adequate post-referral treatment. Economic barriers and distance were frequently mentioned as reasons for not completing referral in this study (manuscript in preparation). The finding that patients who did not complete referral were less likely to die may be a result of less severely sick 
medRxiv preprint doi: https://doi.org/10.1101/2021.09.24.21263966; this version posted September $27,2021$. The copyright holder for this preprint (which was not certified by peer review) is the author/funder, who has granted medRxiv a license to display the preprint in It is made available under a CC-BY-NC-ND 4.0 International license.

patients, or those recovering quickly after a dose of RAS, not being brought to a referral facility. Improved health has previously been reported as a reason for non-compliance with referral advice. ${ }^{20,24}$

However, comprehensive antimalarial treatment after a dose of RAS is crucial as one dose of artesunate alone (or in combination with another only partly effective antimalarial) cannot fully clear an infection., ${ }^{2,25}$ This study found patients receiving post-referral treatment with a parenteral antimalarial (plus ACT) to be significantly less likely to die (or be sick at follow-up). Yet, many patients who successfully completed referral did not receive both parenteral antimalarial treatment and an ACT at the referral facility (Table 2, manuscript in preparation). In Nigeria, parenteral treatment was common but none of the patients received an ACT at the Cottage Hospital. Whether ACT prescriptions provided at referral facilities were purchased and administered could not be verified in this study. Pre-referral treatment with RAS with or without subsequent parenteral artesunate, but without an oral ACT, constitutes artemisinin monotherapy treatment. This is a risk for both resistance development and positive selection of circulating artesmisinin-resistant parasites, the latter of which has been found in Uganda (manuscript in preparation). ${ }^{26}$

All patients included in this study had access to formal health care providers (enrolment criterion) and 42-73\% of deaths occurred in a health facility, often several days after first contact with the formal health system (mean 2.46.3 days). In Nigeria, the CFR among patients enrolled at a PHC exceeded 20\% over several months (mean 18.6\%, data not included) (Supplementary Figure S5). Together, these findings reflect weak health care systems that are often unable to save the lives of severely sick children. In these challenging settings, pre-referral RAS did not appear to have a beneficial health effect despite the potential of this intervention demonstrated under different circumstances. ${ }^{7}$

Introducing pre-referral RAS without ensuring an effective continuum of care (including high referral rates and high-quality post-referral treatment) is unlikely to decrease mortality in settings with a high malaria burden but a weak health system. Conversely, RAS is most likely to be beneficial in locations where initial access to health care may be hampered, but post-referral services are available and of good quality. This is supported by the finding of a moderately beneficial effect in Uganda, where baseline CFR was lowest, the number of CHW per person was highest, accessibility of formal health facilities was best (measured eg. in distance/time to facility), and out of pocket treatment costs were lowest (manuscript in preparation). Evidence from implementing a package of interventions including RAS in Zambia also supports this notion. ${ }^{18}$

\section{Conclusion}

Curbing the remaining burden of malaria mortality remains a top public health priority in countries with a high malaria burden. While pre-referral RAS treatment may have a beneficial health effect for an individual patient who can follow the full continuum of care, this intervention is unlikely to reduce malaria mortality in a population unless underlying health system factors are addressed. The large-scale roll-out of pre-referral RAS must be accompanied by measures to ensure definitive treatment with at least parenteral artesunate and a full course of oral ACT. 
medRxiv preprint doi: https://doi.org/10.1101/2021.09.24.21263966; this version posted September $27,2021$. The copyright holder for this preprint (which was not certified by peer review) is the author/funder, who has granted medRxiv a license to display the preprint in

It is made available under a CC-BY-NC-ND 4.0 International license.

\section{Acknowledgements}

We thank all the children and their caregivers who agreed to participate in this study; the health workers and local and national health authorities who provided their support; our study teams of the School of Public Health in Kinshasa (DRC), Akena Associates (Nigeria), and Makerere University School of Public Health (Uganda); and the colleagues of the local CHAI and UNICEF offices. We greatly appreciate Robert Canavan's editorial support.

\section{Funding}

This study was funded by Unitaid.

\section{Conflict of Interest Statement}

All authors have completed the ICMJE uniform disclosure form at www.icmje.org/coi_disclosure.pdf and declare: all authors had financial support from Unitaid for the submitted work; no financial relationships with any organizations that might have an interest in the submitted work in the previous three years; no other relationships or activities that could appear to have influenced the submitted work.

\section{Data availability}

The data that support the findings of this study are available from the corresponding author upon reasonable request.

\section{References}

1. World Health Organization. World Malaria Report 2020. Geneva: World Health Organization; 2020.

2. World Health Organization. Guidelines for the treatment of malaria - 3rd edition. Geneva: World Health Organization; 2015.

3. Young M, Wolfheim C, Marsh DR, Hammamy D. World Health Organization/United Nations Children's Fund Joint Statement on Integrated Community Case Management: An Equity-Focused Strategy to Improve Access to Essential Treatment Services for Children. The American Society of Tropical Medicine and Hygiene 2012; 87(5_Suppl): 6-10.

4. Coetzer RH, Adeola AM. Assessing the Correlation between Malaria Case Mortality Rates and Access to Health Facilities in the Malaria Region of Vhembe District, South Africa. Journal of Environmental and Public Health 2020; 2020: 8973739.

5. Karra M, Fink G, Canning D. Facility distance and child mortality: a multi-country study of health facility access, service utilization, and child health outcomes. Int J Epidemiol 2017; 46(3): 817-26. 
medRxiv preprint doi: https://doi.org/10.1101/2021.09.24.21263966; this version posted September 27, 2021. The copyright holder for this preprint (which was not certified by peer review) is the author/funder, who has granted medRxiv a license to display the preprint in It is made available under a CC-BY-NC-ND 4.0 International license.

6. de Carvalho LP, Kreidenweiss A, Held J. The preclinical discovery and development of rectal artesunate for the treatment of malaria in young children: a review of the evidence. Expert Opin Drug Discov 2021; 16(1): 13-22.

7. Gomes MF, Faiz MA, Gyapong JO, et al. Pre-referral rectal artesunate to prevent death and disability in severe malaria: a placebo-controlled trial. Lancet 2009; 373(9663): 557-66.

8. Okebe J, Eisenhut M. Pre-referral rectal artesunate for severe malaria. The Cochrane database of systematic reviews 2014; 2014(5): Cd009964.

9. $\quad$ von Seidlein L, Deen JL. Pre-referral rectal artesunate in severe malaria. Lancet 2009; 373(9663): 522-3.

10. Obrist B, Iteba N, Lengeler C, et al. Access to health care in contexts of livelihood insecurity: a framework for analysis and action. PLoS Med 2007; 4(10): e308.

11. World Health Organization. WHO - Prequalification of Medical Products (IVDs, Medicines, Vaccines and Immunization Devices, Vector Control). Geneva: World Health Organization; 2021.

12. CARAMAL Project. Rectal Artesunate Landscaping Assessment Report. Unitaid; 2018.

13. World Health Organization. Global technical strategy for malaria 2016-2030. Geneva: World Health Organization; 2015.

14. Ferrari G, Ntuku HM, Burri C, et al. An operational comparative study of quinine and artesunate for the treatment of severe malaria in hospitals and health centres in the Democratic Republic of Congo: the MATIAS study. Malar J 2015; 14: 226.

15. Dondorp AM, Fanello CI, Hendriksen IC, et al. Artesunate versus quinine in the treatment of severe falciparum malaria in African children (AQUAMAT): an open-label, randomised trial. Lancet 2010; 376(9753): $1647-57$.

16. Fleiss J, Levin B, Paik M. Statistical Methods for Rates and Proportions. 3rd ed. New York: Wiley; 2003.

17. Hirji KF, Premji ZG. Pre-referral rectal artesunate in severe malaria: flawed trial. Trials 2011; 12 : 188.

18. Green C, Quigley P, Kureya T, et al. Use of rectal artesunate for severe malaria at the community level, Zambia. Bull World Health Organ 2019; 97(12): 810-7.

19. Phiri TB, Kaunda-Khangamwa BN, Bauleni A, et al. Feasibility, acceptability and impact of integrating malaria rapid diagnostic tests and pre-referral rectal artesunate into the integrated community case management programme. A pilot study in Mchinji district, Malawi. Malar J 2016; 15: 177.

20. Warsame M, Gyapong M, Mpeka B, et al. Pre-referral Rectal Artesunate Treatment by Community-Based Treatment Providers in Ghana, Guinea-Bissau, Tanzania, and Uganda (Study 18): A Cluster-Randomized Trial. Clin Infect Dis 2016; 63(suppl 5): S312-S21.

21. Awad MI, Alkadru AMY, Behrens RH, Baraka OZ, Eltayeb IB. Descriptive study on the efficacy and safety of artesunate suppository in combination with other antimalarials in the treatment of severe malaria in Sudan. Am J Trop Med Hyg 2003; 68(2): 153-8.

22. Gomes M, Ribeiro I, Warsame M, Karunajeewa H, Petzold M. Rectal artemisinins for malaria: a review of efficacy and safety from individual patient data in clinical studies. BMC Infect Dis 2008; 8: 39.

23. Strachan CE, Nuwa A, Muhangi D, Okui AP, Helinski MEH, Tibenderana JK. Community understanding of the concept of pre-referral treatment and how this impacts on referral related decision-making following the provision of rectal artesunate: a qualitative study in western Uganda. BMC Health Serv Res 2018; 18(1): 470.

24. Simba DO, Kakoko DC, Warsame M, et al. Understanding caretakers' dilemma in deciding whether or not to adhere with referral advice after pre-referral treatment with rectal artesunate. Malar J 2010; 9: 123. 
medRxiv preprint doi: https://doi.org/10.1101/2021.09.24.21263966; this version posted September 27, 2021. The copyright holder for this preprint (which was not certified by peer review) is the author/funder, who has granted medRxiv a license to display the preprint in It is made available under a CC-BY-NC-ND 4.0 International license.

25. Barnes KI, Mwenechanya J, Tembo M, et al. Efficacy of rectal artesunate compared with parenteral quinine in initial treatment of moderately severe malaria in African children and adults: a randomised study. The Lancet 2004; 363(9421): 1598-605.

26. Ndwiga L, Kimenyi KM, Wamae K, et al. A review of the frequencies of Plasmodium falciparum Kelch 13 artemisinin resistance mutations in Africa. Int J Parasitol Drugs Drug Resist 2021; 16: 155-61. 